\title{
Reflections on a career in paediatric pharmacy
}

\author{
Sharon Conroy
}

I was very honoured when asked by EJHP and the editor in chief to 'pioneer' the first themed issue in EJHP focusing on paediatrics, as this is a subject very close to my heart. Please allow me to give you a bit of background as to why and to persuade you to read this edition whether you're a paediatric pharmacist or not.

Monday, 1 September 1986 was the start of a 'new career' and, in a way, a 'new life' for me. That was the day that I took up a post as 'staff pharmacist' at a small Victorian children's hospital in the East Midlands area of England (sadly now demolished). Until that time I had been a 'resident' pharmacist at a busy general hospital, and after 3 years was frankly fed up of being bleeped in the middle of the night and getting out of my bed to supply drugs and sort out problems. My thoughts when I was told that I had been successful in getting the children's hospital job were "great, no more bleeps, no more living in the nurse's home (though that had been fun!) and ... I don't really like kids but I'll do this job until something better comes along"!

In 1986 the pharmacy department was in the basement of the hospital; we could just see people's feet walking past the window high above us. It was freezing in winter and hot in summer (so hot one year that we had to hire portable airconditioning units as I was concerned that the drugs would deteriorate in the heat). We saw the occasional rat, cockroach and a regular visiting tramp outside the back door (and once a rat in the waiting room -yuk!). It was a bit scary on dark winter evenings being down there alone when my technician had gone home. Despite all this I loved working there.

Why-I hear you ask? Is she mad? When I first started the job I asked myself the same thing on a regular basis. Having worked closely with medical and nursing staff and been very much part of the multidisciplinary team in my residency job, performing clinical pharmacy duties and attending consultant ward rounds, I was bemused when challenged in the

Correspondence to Dr Sharon Conroy, Department of Child Health, University of Nottingham, School of Medicine, Royal Derby Hospital, Uttoxeter Road, Derby DE22 3DT, UK; Sharon.Conroy@nottingham.ac.uk children's hospital for 'wandering around the wards', being asked 'why do you need to look in the medical notes?' and 'why do you need a copy of the treatment protocol?' etc. My predecessor had been in post for many years and was of the 'old school', where pharmacists rarely left the dispensary and obligingly did the doctor's bidding with little question. Who then was this young upstart who dared to leave 'the dungeon' (as pharmacy affectionately became known) to look at drug charts and notes and even question the doctor's judgement?!

I was treated with suspicion for a week or two until I intercepted a potentially serious error on an oncology patient's drug chart (having checked it against the protocol which I had had to sneakily 'borrow' to photocopy when the consultant wasn't around). After discussing and resolving the error with the medical team as well as highlighting several other interventions made in the first few weeks, I rapidly became a respected part of the team. The nurses' attitudes changed from suspicion to being reassured when giving medicines if they were endorsed by the pharmacy 'green pen'. That was 28 years ago, and in that time the hospital has moved to become part of a new big general hospital and I have changed jobs to working for the University of Nottingham, undertaking research and teaching the use of medicines in children. I still however visit the wards as a 'proper' pharmacist 1 day each week, which I still love.

Since 1986 things have changed a lot. One event that has had a long lasting effect on my work was the 'birth' of the Neonatal and Paediatric Pharmacists Group (NPPG) (http://www.nppg.org.uk) in 1994, which celebrates its 20th year at its conference in November. I am so proud of this organisation and its achievements and have been privileged to serve as its Chair, Secretary and Research lead in the last 15 years. Among many things, NPPG provides its members with an active online discussion forum where questions and problems can be shared and discussed on a daily basis. This is a huge support, especially for pharmacists working alone or in small departments such as mine. Pre-NPPG I had to telephone an unknown person in one of the large children's hospitals to seek advice on a regular basis. Now such queries can be sent online to the paediatric pharmacy world (which in the UK at least is fairly small) and usually a helpful reply will follow quickly. In addition the annual conference provides an opportunity for sharing work and experiences, networking and getting to know people, so that members have a good idea who to contact or who is answering them on the discussion forum, which makes things so much easier on a daily basis. Conference abstracts are published online on the Archives of Disease in Childhood journal website (http://adc.bmj.com/).

Through NPPG I have had the pleasure of meeting and working closely with some wonderful and dedicated people passionate about their work and improving pharmaceutical care for children. NPPG has worked closely with the UK paediatricians' professional body (Royal College of Paediatrics and Child Health (RCPCH)) for many years. Together we have published two editions of Medicines for Children, ${ }^{1}$ a much loved peer reviewed and nationally accepted reference source. This was replaced in 2005 by the British National Formulary for Children, ${ }^{2}$ now produced annually on a more sustainable basis.

NPPG is also consulted on paediatric drug therapy issues on a regular basis at a national level, and is working closely with the Royal Pharmaceutical Society in London to develop professional curricula which aim to define what pharmacists need to know and be able to do in their particular area of practice, and to provide support to guide them to the evidence and experience they need to demonstrate advancement and progression. ${ }^{3}$ Membership is open to any pharmacist/technician, whether paediatrics is your chosen speciality, just a part of your job or even if it is just an interest. We have members from across the world including Europe, Australasia and Africa.

The challenges of working in paediatric pharmacy are many. Dose calculations in children can be complicated for many reasons, including: patient's immaturity; rapidly changing pharmacokinetics; lack of suitable dose forms with the subsequent need to use unlicensed and off label drugs on a regular basis; and patient weights and ages ranging from premature neonates $<500 \mathrm{~g}$ to obese adolescents of $120 \mathrm{~kg}$ (>200-fold difference), who both may be in the same hospital on the same day. Chloe Benn explores many of these issues in an article ${ }^{4}$ which should be useful to many readers. 
Paediatrics is considered a specialty by many, but being a paediatric pharmacist actually means being a generalist working with a very special patient group. Children do suffer from some diseases not seen in adults, for example metabolic diseases, a complex area explained by Reena Patel. ${ }^{5}$ On the other hand, children, like adults, also have respiratory, cardiac, liver, renal, musculoskeletal and infectious diseases etc.; most need to be treated with medicines, many of which are not licensed for children. One such disease is ulcerative colitis; the role of infliximab in children with this disease is described in Szerszen and Horton's article ${ }^{6}$ highlighting some of the challenges we and the industry face. ${ }^{7}$

Unfortunately, due to the complexities alluded to above, errors do happen and Burridge $e t a l^{8}$ explore some of the ways that hospitals approach and try to reduce these. Studies of medication errors in children have increased dramatically in recent years and prescribing errors have been estimated to occur in $13.2 \%$ of medication orders. ${ }^{8}$ In addition non-medical prescribing is becoming more common in a number of countries. Peter Mulholland tells us about his experiences of becoming a pharmacist prescriber in a neonatal intensive care unit. ${ }^{9}$

Sutherland and Playfor discuss the use of safe and appropriate intravenous fluids in children. ${ }^{10}$ With at least four deaths (and a near miss) following neurological injury from hospital-acquired hyponatraemia reported in the UK since 2000, and more than 50 cases of serious injury or child death associated with the administration of hypotonic infusions cited in the international literature, this issue was subject to national patient safety initiatives in the UK in $2007 .{ }^{11}$ Ask yourself-how many of you routinely check intravenous fluid prescriptions, including choice of fluid, rate prescribed, rate actually being administered and patient's weight and urea and electrolyte levels? It's certainly an area where I personally find regular errors, particularly since most of these fluids are prescribed by junior medical staff.

As already mentioned, the need to use unlicensed and off label medicines in children brings many problems, ${ }^{12}$ one of which is the lack of appropriate patient and family information. Gutermann and Kaestli $^{13}$ explore different aspects of this in their articles and the NPPG is working very hard with the $\mathrm{RCPCH}$ to try to address the problem. In collaboration with the children's charity Wellchild, we have set up a website aimed at families and healthcare professionals. This website ${ }^{14}$ provides free practical and reliable advice about medicines for children.

In conclusion, I hope that you enjoy this paediatric themed edition, whether you work in paediatrics or not. For those of you who are undecided on your chosen career, let me go back to my thoughts from 1986 of 'I'll do this job until something better comes along'... well... 28 years on nothing better did come along... and I don't think it ever will... I would recommend paediatrics to you all!

Competing interests None.

Provenance and peer review Commissioned; internally peer reviewed.

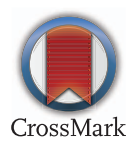

To cite Conroy S. Eur J Hosp Pharm 2014;21:317318.

Accepted 25 September 2014

Eur J Hosp Pharm 2014;21:317-318.

doi:10.1136/ejhpharm-2014-000575

\section{REFERENCES}

1 Royal College of Paediatrics and Child Health and the Neonatal and Paediatric Pharmacists Group. (1999 and 2003) Medicines for Children. London: RCPCH Publications.

2 British Medical Association, Royal Pharmaceutical Society of Great Britain, Royal College of Paediatrics and Child Health and the Neonatal and Paediatric Pharmacists Group. BNF for children 2014:15. London: BMJ Publishing Group.

3 http://www.rpharms.com/development/faculty.asp (accessed 25 Sep 2014).

4 Benn C. Optimising medicines for children: considerations for clinical pharmacists. Eur J Hosp Pharm 2014;21:350-4.

5 Patel RD. Metabolic diseases - an overview and key messages for pharmacists. Eur J Hosp Pharm 2014;21:355-60.

6 Horton ER, Szerszen M. Infliximab for the treatment of pediatric ulcerative colitis. Eur J Hosp Pharm 2014;21:361-6.

7 Ghaleb MA, Barber N, Dean Franklin B, et al. The incidence and nature of prescribing and medication administration errors in paediatric inpatients. Arch Dis Child 2010;95:113-18.

8 Burridge AM, Wilson K, Terry D. Support for paediatric prescribers: what's discussed at hospital board level? Eur J Hosp Pharm 2014;21:330-4.

9 Mulholland P. Pharmacists as non-medical prescribers - what role can they play? Eur J Hosp Pharm 2014;21:335-8.

10 Sutherland A, Playfor S. Safe and appropriate intravenous fluids for children. Eur J Hosp Pharm 2014;21:367-71.

11 National Patient Safety Agency. Patient safety alert: reducing the risk of hyponatraemia when administering intravenous infusions to children. Central Alert System (CAS) reference NPSA/2007/22. 2007. London, UK. http://www.nrls.npsa.nhs.uk/ resources/?entryid45=59809 (accessed 23 Sep 2014).

12 Conroy S. Practical aspects of unlicensed and off-label use of medicines in children. EJHP Pract 2008;14:64-6.

13 Gutermann L, Decottignies A, Sharif K, et al. Parents and carers of patients who had liver transplants: opinions and experiences of medication issues. Eur $\mathrm{J}$ Hosp Pharm 2014;21:339-43.

14 http://www.medicinesforchildren.org.uk/ (accessed 24 Sep 2014). 